\title{
Evidence for infection but not transmission of Zika virus by Aedes albopictus (Diptera: Culicidae) from Spain
}

Luis M. Hernández-Triana 1* Elsa Barrero', Sarah Delacour-Estrella², Ignacio Ruiz-Arrondo ${ }^{3}$, Javier Lucientes², Maria del Mar Fernández de Marco ${ }^{1}$, Leigh Thorne ${ }^{1}$, Sarah Lumley ${ }^{4}$, Nicholas Johnson ${ }^{1,5}$, Karen L. Mansfield ${ }^{1}$ and Anthony R. Fooks ${ }^{1,6}$

\begin{abstract}
Background: A number of mosquito-borne viruses such as dengue virus (DENV), Usutu virus (USUV), West Nile virus (WNV) are autochthonously transmitted in Europe and six invasive mosquito species have been detected in this temperate region. This has increased the risk for the emergence of further mosquito-borne diseases. However, there is a paucity of information on whether European populations of invasive mosquito species are competent to transmit arboviruses. In this study, the susceptibility of Aedes albopictus originating from Spain and a laboratory-adapted colony of Aedes aegypti, was assessed for infection with, and transmission of Zika virus (ZIKV). Vertical transmission in both species was also assessed.

Methods: Aedes albopictus colonised from eggs collected in Spain and an existing colony of Ae. aegypti were fed infectious blood meals containing ZIKV (Polynesian strain) at $1.6 \times 10^{7} \mathrm{PFU} / \mathrm{ml}$. Blood-fed mosquitoes were separated and maintained at $20^{\circ} \mathrm{C}$ or $25^{\circ} \mathrm{C}$. Legs, saliva and bodies were sampled from specimens at 7,14 and 21 days postinfection (dpi) in order to determine infection, dissemination and transmission rates. All samples were analysed by real-time RT-PCR using primers targeting the ZIKV NS1 gene.

Results: At $14 \mathrm{dpi}$ and $21 \mathrm{dpi}$, ZIKV RNA was detected in the bodies of both species at both temperatures. However, live virus only was detected in the saliva of Ae. aegypti at $25^{\circ} \mathrm{C}$ with a transmission rate of $44 \%$. No evidence for virus expectoration was obtained for Ae. albopictus under any condition. Notably, ZIKV RNA was not detectable in the saliva of Ae aegypti at $20^{\circ} \mathrm{C}$ after 21 days. No vertical transmission of ZIKV was detected in this study.

Conclusions: Experimental infection of Ae. albopictus colonized from Spain with ZIKV did not result in expectoration of virus in saliva in contrast to results for Ae. aegypti. No evidence of vertical transmission of virus was observed in this study. This suggests that this strain of Ae. albopictus is not competent for ZIKV transmission under the conditions tested.
\end{abstract}

Keywords: Aedes aegypti, Aedes albopictus, Zika virus, Vector competence, Spain

\footnotetext{
*Correspondence: luis.hernandez-triana@apha.gov.uk

${ }^{1}$ Wildlife Zoonoses and Vector-borne Diseases Research Group, Animal and Plant Health Agency, Woodham Lane, New Haw, Addlestone, Surrey KT15 3NB, UK

Full list of author information is available at the end of the article
} 


\section{Background}

ZIKV (Flaviviridae, Flavivirus) is an emergent mosquitoborne disease, with a natural transmission cycle involving mainly Aedes species and monkeys [1,2]. The virus was first isolated from a rhesus macaque monkey (Macaca mulatta) and Aedes africanus mosquitoes in the Zika forest of Uganda in 1947 [3]. Humans are susceptible to infection with clinical symptoms varying from asymptomatic to an influenza or dengue-like syndrome associated with fever, headache, malaise and maculopapular rash [4]. However, epidemiological investigations of the recent outbreak in Brazil and earlier outbreaks in Asia and Polynesia has linked ZIKV infection to clinical manifestations such as neonatal microcephaly and increased neurological disorders such as the Guillain-Barré Syndrome [5]. This prompted the World Health Organization (WHO) to declare the ZIKV epidemic a Public Health Emergency of International Concern in 2016 [6, 7].

Aedes aegypti is considered the primary vector of ZIKV and Ae. albopictus the secondary vector. However, this is not directly reflected by the results in vector competence studies in the literature, with some studies showing that Ae. albopictus can be an efficient vector of ZIKV, especially at higher temperatures, with the species being able to vertically transmit the virus to their progeny [8]. In addition to ZIKV, Ae. aegypti and Ae. albopictus can transmit many other arboviruses such as DENV, chikungunya virus (CHIKV), Mayaro virus (MAYV), yellow fever virus (YFV) and WNV [9-11].

Aedes albopictus is common in tropical and subtropical regions of the world [12], but has managed to establish in temperate regions due to human activity such as the importation of used tyres and translocation of adult mosquitoes in cars $[13,14]$. In Europe, the species is widespread throughout the Mediterranean Basin, and it is currently expanding its range to northern latitudes $[15,16]$. In Spain, Ae. albopictus is commonly detected in coastal areas, but has colonized much cooler areas of northern Spain such as Aragón [17, 18]. Due to the potential public health risk of ZIKV being introduced into Spain and other countries in Europe [19], this study has evaluated the vector competence of a Spanish population of Ae. albopictus for the Asian genotype of ZIKV at two temperatures. In parallel, Ae. aegypti was used as a control vector with known competence for ZIKV. Furthermore, we have also assessed the potential of these two mosquito species to transmit ZIKV vertically at both temperatures.

\section{Methods}

\section{Colonization of mosquitoes}

Aedes albopictus eggs were collected in ovitraps in 2009 at Baix Llobregat municipality, Barcelona province,
Spain, and a colony was established at the Faculty of Veterinary Medicine, University of Zaragoza in the same year [20]. Aedes aegypti (Biogents, http://www.eu.bioge nts.com) supplied by Dr Andrea Drago and originally colonised from mosquitoes from Cuba (year of colonization unknown), was used for comparison. Eggs were then sent to the Animal and Plant Health Agency, United Kingdom, and a colony was established within the high biosecurity containment facility at the agency in 2017. For the maintenance of mosquitoes, we followed the protocols of Alarcón-Elbal et al. [20], Hernández-Triana et al. [21] and Puggioli et al. [22].

\section{Cells and virus}

ZIKV (strain H/PPF/2013 isolated in French Polynesia; GenBank: KJ776791) was obtained through the EVAg consortium (https://www.european-virus-archive.com). This virus is closely related to that currently circulating in South America [23]. The strain was grown and passaged at $37^{\circ} \mathrm{C}$ in Vero cells. The strain was titrated in Vero cells following the protocol of Hernández-Triana et al. [21].

\section{Assessment of vector competence and vertical transmission}

Three to five day old adult female Ae. albopictus or Ae. aegypti (number of generations from the seed colony unknown) were allowed to feed with a Hemotek feeding system (Hemotek Ltd, Blackburn, UK) at room temperature for a maximum of $2 \mathrm{~h}$ on an infectious blood meal containing defibrinated horse blood, adenosine $5^{\prime}$-triphosphate (final concentration $20 \mathrm{mM}$ ) and ZIKV (at $1.6 \times 10^{7} \mathrm{PFU} / \mathrm{ml}$ ). Mosquito infection, immobilization, processing of specimens at different days postinfection (dpi), and assessment of vector competence (infection, dissemination and transmission rates) was achieved through published protocols [21]. Infection rate was calculated by dividing the number of ZIKV RT-PCR positive mosquito bodies (abdomen/thorax) by the total number of blood-fed individuals. Dissemination rate was calculated by dividing as the number ZIKV RT-PCR positive legs by the number of positive bodies. Transmission rate was calculated by dividing the number of ZIKV RTPCR positive saliva expectorate samples by the number of positive leg samples (Table 1).

For the assessment of vertical transmission, three days after the first ZIKV infectious bloodmeal, a small plastic bowl containing water and filter paper was placed inside Insect Bugdorm cages (http://www.bugzarre.co.uk) for oviposition. The filter paper was maintained for 7 days for completion of the first gonotrophic cycle at dpi 7, after which they were collected and dried down. At this point, non-infectious blood was offered to mosquitoes and the same process was repeated twice for completion 
Table 1 ZIKV infection, dissemination and transmission of challenged Ae. albopictus Spain and Ae. aegypti Biogens with ZIKV at $20^{\circ} \mathrm{C}$ and $25^{\circ} \mathrm{C}$

\begin{tabular}{|c|c|c|c|c|c|c|c|}
\hline & & \multicolumn{3}{|l|}{$20^{\circ} \mathrm{C}$} & \multicolumn{3}{|l|}{$25^{\circ} \mathrm{C}$} \\
\hline & & Dpi 7 (\%) & Dpi 14 (\%) & Dpi 21 (\%) & Dpi 7 (\%) & Dpi 14 (\%) & Dpi 21 (\%) \\
\hline \multirow[t]{3}{*}{ Ae. albopictus } & Infection (Body) & $4 / 9(45 \%)$ & $5 / 16(31.2 \%)$ & $2 / 15(13.3 \%)$ & 7/7 (100\%) & $6 / 10(60 \%)$ & $0 / 16$ \\
\hline & Dissemination (Legs) & $0 / 4$ & $0 / 5$ & $0 / 2$ & 4/7 (54\%) & $0 / 6$ & 0 \\
\hline & Transmission (Saliva) & 0 & 0 & 0 & $0 / 4$ & 0 & 0 \\
\hline \multirow[t]{3}{*}{ Ae. aegypti } & Infection (Body) & $11 / 25(44 \%)$ & $12 / 30(40 \%)$ & $4 / 26(15.3 \%)$ & $12 / 22(55 \%)$ & 15/23 (65.2\%) & $12 / 18(67 \%)$ \\
\hline & Dissemination (Legs) & 7/11 (63\%) & $7 / 12(58 \%)$ & $0 / 4$ & $5 / 12(41 \%)$ & $12 / 15(80 \%)$ & $9 / 12(75 \%)$ \\
\hline & Transmission (Saliva) & $5 / 7(71 \%)$ & $3 / 7(42 \%)$ & 0 & $5 / 5(100 \%)$ & $5 / 12(41 \%)$ & $5 / 9(55 \%)$ \\
\hline
\end{tabular}

Abbreviation: dpi, days pos-infection

Table 2 Number of pools and specimens per life stage and temperature from the $\mathrm{F} 1$ of Ae. albopictus Spain and Ae. aegypti Biogen tested by qRT-PCR assay to detect ZIKV Asian genotype

\begin{tabular}{lll}
\hline Species/Temperature & Life stage & No. of pools \\
\hline Aedes albopictus $/ 20^{\circ} \mathrm{C}$ & Larvae & na \\
& Pupae & na \\
& Males & 1 \\
Aedes albopictus $/ 25^{\circ} \mathrm{C}$ & Females & 1 \\
& Larvae & 2 \\
& Pupae & 3 \\
Aedes aegypti/20 ${ }^{\circ} \mathrm{C}$ & Males & 4 \\
& Females & 9 \\
& Larvae & 2 \\
Aedes aegypti/ $25^{\circ} \mathrm{C}$ & Pupae & 2 \\
& Males & 1 \\
& Females & 1 \\
& Larvae & 19 \\
& Pupae & 8 \\
& Males & 11 \\
\hline
\end{tabular}

of the second (dpi 14) and third (dpi 21) gonotrophic cycles. Eggs were pooled by species and temperature, and placed to hatch and maintained in the insectary following similar published protocols [21] in order obtain F1 progeny, with the exception that eggs collected in filter papers embedded in water contained in transparent plastic bowls. Cohorts of larvae, pupae, males and females were reared and pooled prior to testing for ZIKV as detailed in Table 2.

\section{Processing of samples for reverse transcription (RT) PCR}

RNA from larvae, pupae, legs/wings, saliva and body samples of Ae. albopictus and Ae. aegypti was extracted using TRIzol (http://www.tools.thermofisher.com) as previously described in Hernández-Triana et al. [21].
Briefly, specimens were homogenized by adding a $5 \mathrm{~mm}$ metallic bead to each tube and using a Qiagen Tissue Lyser (model Retsch MM301) with a tissue disruption speed of $25 \mathrm{MHz}$ for $3 \mathrm{~min}$. All tubes were then centrifuged for $5 \mathrm{~min}$ at $14,000 \times \mathrm{rpm}$ and $30 \mu \mathrm{l}$ of supernatant was collected for virus isolation assays; the RNA pellet was eluted in $20 \mu \mathrm{l}$ of nuclease-free water. ZIKV RNA was detected using a semi-quantitative reverse transcription (RT)-PCR assay targeting a 213 nucleotide region of the NS1 gene using a newly designed primers ZIKVENVForward: 5'-AAG CAY TGG TTG GTK CAC A-3'; ZIKVENV-Reverse: $5^{\prime}$-CAC CAT CCA TCT CAG CCT3'; ZIKENV-Probe: [6FAM]AAC TCC ACA YTG GA ACA ACA A[TAM]. The RT-PCR was performed using $\mathrm{iTaq}^{\mathrm{TM}}$ Universal Probes One-Step Kit (Bio-Rad) using an MxPro 3005P thermal cycler (Stratagene) in a $25 \mu \mathrm{l}$ reaction mix: RNase-free water $(7 \mu \mathrm{l}) ; 2 \times$ iTaq universal probes reaction mix $(12 \mu \mathrm{l}) ; 1 \mu \mathrm{l}$ of each primer and probe at final concentration of $10 \mathrm{pmol} / \mu \mathrm{l}$; and $1 \mu \mathrm{l}$ of iScript RT Mix Enzyme for One Step, and $2 \mu$ of template RNA. The conditions were as follows: Reverse transcription $50{ }^{\circ} \mathrm{C}$ for $10 \mathrm{~min}$; reverse transcriptase inactivation $95^{\circ} \mathrm{C}$ for $5 \mathrm{~min}$; and PCR amplification and detection 40 cycles consisting of $95^{\circ} \mathrm{C}$ for $10 \mathrm{~s}, 55^{\circ} \mathrm{C}$ for $30 \mathrm{~s}$.

\section{Virus isolation and titration}

Plaque assays were performed following the protocol of [20] on infectious pre- and post-feed blood samples to confirm the titre of virus provided, and also on representative saliva and abdomen samples which were ZIKV positive by PCR. A ten-fold dilution series of supernatant of the homogenized body parts or salivary secretions $(30 \mu \mathrm{l})$ was prepared, and dispensed onto a confluent monolayer of Vero cells on a 12-well plate $\left(\right.$ Costar $^{\circledR}$, Corning Life Sciences, Massachusetts, USA). The plates were incubated at $37^{\circ} \mathrm{C}$ in an atmosphere of $5 \% \mathrm{CO}_{2}$ for $3 \mathrm{~h}$. After incubation, 1-1.5 ml overlay of warmed 3\% carboxymethylcellulose $(\mathrm{CMC})$ in $250 \mathrm{ml} 2 \times$ EMEM mix (Deionised 
water, $7.5 \%$ sodium bicarbonate, HEPES $1 \mathrm{M}$, L-glutamine $200 \mathrm{mM}$, FBS, antibiotics (penicillin and streptomycin), and $10 \times$ MEME-E) were added to each well. After 7 days incubation, $1 \mathrm{ml}$ of $10 \%$ neutral buffered formalin solution was added to each well and the plates left for least 3 $\mathrm{h}$ to complete virus inactivation. Wells were stained with $200 \mu \mathrm{l}$ of $2.3 \%$ crystal violet solution.

\section{Results}

Two Aedes species, Ae. albopictus and Ae. aegypti, were orally infected to investigate their vector competence for an Asian strain of ZIKV. Under our experimental conditions, female Ae. albopictus fed poorly, therefore the results from four experiments were combined in order to obtain sufficient numbers of infected mosquitoes for downstream analysis. In total 300 female Ae. aegypti and 700 female $A e$. albopictus were offered an infectious bloodmeal containing ZIKV, resulting in feeding rates of $61 \%$ and $24 \%$, respectively.

ZIKV nucleic acid was detected by RT-PCR in body samples of both species at $20^{\circ} \mathrm{C}$ and $25{ }^{\circ} \mathrm{C}$; however, percentages of RNA detection varied for each species. In $A e$. albopictus at $20{ }^{\circ} \mathrm{C}$, ZIKV RNA was detected in $45 \%$ of samples at dpi $7,31 \%$ of samples at $14 \mathrm{dpi}$, and $13.35 \%$ of samples at $21 \mathrm{dpi}$. Conversely, at a temperature of $25{ }^{\circ} \mathrm{C}$, infection was only detected at dpi 7 (100\%) and dpi 14 (60\%) (Table 1). Dissemination was only encountered at dpi 7 at $25{ }^{\circ} \mathrm{C}$; no ZIKV RNA was detected in the saliva of Ae. albopictus mosquitoes at any time point. Aedes aegypti showed higher infection rates at both temperatures and across all dpi (Table 1 ). At $20{ }^{\circ} \mathrm{C}$, dissemination rates ranged from $63 \%$ at dpi 7 and $58 \%$ at dpi 14 ; no dissemination was detected at dpi 21 . Contrarily, at $25{ }^{\circ} \mathrm{C}$, dissemination was detected at all dpi ranging from $41 \%$ (dpi 7), 80\% (dpi 14) and 75\% (dpi 21). For both temperatures, ZIKV RNA was detected in the saliva in this species (Table 1), except at $20{ }^{\circ} \mathrm{C} / \mathrm{dpi} 21$. Nonetheless, slightly higher transmission rates were seen at $25^{\circ} \mathrm{C} / \mathrm{dpi}$ 7 , dpi 14 and dpi 21 compared to those obtained at $20^{\circ} \mathrm{C}$ (dpi 7, dpi 14 and dpi 21). The presence of ZIKV in Ae. aegypti saliva was confirmed by plaque assay with titres ranging from $3.7 \times 10^{4}$ to $7.4-10^{6} \mathrm{PFU} / \mathrm{ml}$.

Blood-fed females of Ae. aegypti and Ae. albopictus were allowed to breed and oviposit, and the F1 generation of all different life stages (larva, pupa, adults) after ZIKV-infectious blood were sampled. Pools for both species were tested for the presence of ZIKV RNA. All pools tested from both species were negative (Table 2).

\section{Discussion}

Due to its abundance, anthropophilic biting behaviour and ability to vector numerous arboviruses, the presence of Ae. albopictus represents a clear risk for the transmission of viruses such as ZIKV, especially if viraemic humans travel into infested areas. The global spread of ZIKV has in recent years dramatically increased the risk of viraemic individuals entering Europe [24] and thus encountering vectors. However, studies to assess different populations of Ae. albopictus have revealed varying levels of vector competence [2, 25, 26]. Aedes albopictus in Spain has shown a rapid increase in its distribution range in recent years, which has been facilitated in a large part by passive transportation in cars [13]. In order to assess the capacity of this population to transmit ZIKV, colonised Ae. albopictus from the Baix Lobregat municipality in northern Spain were orally fed a blood meal containing ZIKV and assessed for their ability to become infected, expectorate virus (a surrogate measure of bite transmission) and vertically transmit virus at $20{ }^{\circ} \mathrm{C}$ and $25^{\circ} \mathrm{C}$, temperatures that are consistently reached in northern Spain during the summer months. Infection did take place at both temperatures with an increase in efficiency at the higher temperature (Table 1). However, there was little virus dissemination and no expectoration in saliva for Ae. albopictus in direct contrast to the observations for the established vector for ZIKV, Ae. aegypti. This corroborates similar finding for Ae. albopictus populations in Germany [27] and Italy [24].

However, an increase in incubation temperature at or greater than $27^{\circ} \mathrm{C}$ has been shown to increase the infection and transmission rates of ZIKV by Ae. albopicutus $[5,28,29]$. This was also demonstrated in a recent paper by Gutiérrez-López et al. [30] from Ae. albopictus F2 adults obtained from wild-caught eggs in Barcelona, Spain. In contrast to our results, these authors found that this population of Ae. albopictus was a vector of ZIKV and showed high levels of vertical transmission, which could be explained by variation in within-species population vector competence, the different virus strains and temperature used [31, 32]. A similar temperature effect has been shown for ZIKV transmission by German populations of Ae. japonicus [31]. In general, all in all, it seems that temperature might play be an important role for the vector competence in Ae. albopictus, and other Aedes species as discussed by Tesla et al. [33].

The relatively small number of specimens tested during experiments of ZIKV vertically transmission was due to the low number of emerged larvae and adults (Table 2). Nonetheless, the analysis of F1 offspring of both species showed no evidence of vertical transmission of ZIKV (Table 2). A similar observation has been made for Ae. albopictus from Italy [23], although experiments with a north American strain of the species did detect ZIKV in 1 of 84 first generation larvae, implying that vertical transmission is possible [8]. At present, few studies exist that have intensively investigated the efficiency of transovarial (vertical) and venereal 
(horizontal) transmission of ZIKV either in Ae. albopictus or Ae. aegypti. However, it is still possible that these forms of transmission occur at low levels to support ZIKV persistence.

\section{Conclusions}

The colonised line of Ae. albopictus from northern Spain demonstrated infection with ZIKV and dissemination; however, no evidence for expectoration in saliva was detected suggesting that this strain is not a competent vector for ZIKV at the conditions assessed in this study. This is in contrast to the established vector of the virus Ae. aegypti. No evidence of vertical transmission in either species was detected at $20^{\circ} \mathrm{C}$ or $25^{\circ} \mathrm{C}$ in this study.

\section{Acknowledgements}

The authors acknowledge Andrea Drago, Entostudio, for providing Ae. aegypti eggs of (Biogents) and Fiona McCracken (APHA) for technical support.

\section{Funding}

Funding was provided by the EU Framework Horizon 2020 Innovation Grant EVAg (No. 653316) and the Department for Environment Food and Rural Affairs (DEFRA), Scottish Government and Welsh Government through grants SV3045 and SE4113.

\section{Availability of data and materials}

All data that this paper relies upon is presented within this article.

\section{Authors' contributions}

Obtained funding: ARF, NJ and LMHT. Conceived and designed the experiments: LMHT and KLM. Colonised the mosquito species: SD, IRA and JL. Developed ZIKV RT-PCR: NJ. Performed the experiments: LMHT, EB and MF. Analyzed the data: $L M H T, E B, S D, I R A, J L, M F, L T, K L M, S L, N J$ and ARF. Wrote the first draft of the paper: LMHT. All authors read and approved the final manuscript.

\section{Ethics approval and consent to participate}

Not applicable.

\section{Consent for publication}

Not applicable.

\section{Competing interests}

The authors declare that they have no competing interests.

\section{Publisher's Note}

Springer Nature remains neutral with regard to jurisdictional claims in published maps and institutional affiliations.

\section{Author details \\ ${ }^{1}$ Wild life Zoonoses and Vector-borne Diseases Research Group, Anima and Plant Health Agency, Woodham Lane, New Haw, Addlestone, Surrey KT15 3NB, UK. ${ }^{2}$ Department of Animal Pathology, Faculty of Veterinary Medicine, University of Zaragoza, Zaragoza, Spain. ${ }^{3}$ Center for Rickettsiosis and Vec- tor-Borne Diseases Group, Hospital Universitario San Pedro-CIBIR, Logroño, Spain. ${ }^{4}$ Public Health England, Porton Down, Salisbury SP4 0JG, UK. ${ }^{5}$ Faculty of Health and Medicine, University of Surrey, Guildford, Surrey GU27XH, UK. ${ }^{6}$ Department of Clinical Infection, Microbiology and Immunology, Institute of Infection and Global Health, University of Liverpool, Liverpool, UK.}

Received: 20 January 2019 Accepted: 29 April 2019

Published online: 03 May 2019

\section{References}

1. Campos SS, Fernandes RS, Dos Santos AAC, de Miranda RM, Telleria EL, Ferreira-de-Brito A, et al. Zika virus can be venereally transmitted between Aedes aegypti mosquitoes. Parasites Vectors. 2017;15:605.

2. Chouin-Carneiro T, Vega-Rua A, Vazeille M, Yebakima A, Girod R, Goindin D, et al. Differential susceptibilities of Aedes aegypti and Aedes albopictus from the Americas to Zika virus. PLoS Negl Trop Dis. 2016;10:e0004543.

3. Dick GW, Kitchen SF, Haddow AJ. Zika virus. I. Isolations and serological specificity. Trans R Soc Trop Med Hyg. 1952:46:509-20.

4. Hussain A, Ali F, Latiwesh OB, Hussain S. A comprehensive review of the manifestations and pathogenesis of Zika virus in neonates and adults. Cureus. 2018;10:e3290.

5. Carod-Artal FJ. Neurological complications of Zika virus infection. Expert Rev Anti Infect Ther. 2018;16:399-410.

6. Musso D, Gubler DJ. Zika virus. Clin Microbiol Rev. 2016;29:487-524.

7. Elliott R, Banerjee T, Santra S. Zika: an emerging disease requiring prevention and awareness. PLoS Negl Trop Dis. 2018;12:e0006486.

8. Ciota AT, Bialosuknia SM, Ehrbar DJ, Kramer LD. Vertical transmission of Zika virus by Aedes aegypti and Ae. albopictus mosquitoes. Emerg Infect Dis. 2017:23:880-2.

9. Jupille H, Seixas G, Mousson L, Sousa CA, Failloux AB. Zika virus, a new threat for Europe? PLoS Negl Trop Dis. 2016;10:e0004901.

10. Becker N, Petrić D, Zgomba M, Boase C, Madon M, Dahl C, et al. Mosquitoes and their control. 2nd ed. Berlin: Springer; 2010.

11. Lambrechts L, Scott TW, Gubler DJ. Consequences of the expanding global distribution of Aedes albopictus for dengue virus transmission. PLoS Negl Trop Dis. 2010;4:e646.

12. Benedict MQ, Levine RS, Hawley WA, Lounibos LP. Spread of the tiger: global risk of invasion by the mosquito Aedes albopictus. Vector Borne Zoonotic Dis. 2007;7:76-85.

13. Reiter P, Sprenger D. The used tire trade: a mechanism for the worldwide dispersal of container breeding mosquitoes. J Am Mosq Control Assoc. 1987;3:494-501.

14. Eritja R, Palmer JRB, Roiz D, Sanpera-Calbet I, Bartumeus F. Direct evidence of adult Aedes albopictus dispersal by car. Sci Rep. 2017;24:14399.

15. Medlock JM, Hansford K, Schaffner F, Versteirt V, Hendrick G, Zeller H, et al. A review of the invasive mosquitoes in Europe: ecology, public health risks, and control options. Vector Borne Zoonotic Dis. 2012:12:435-47.

16. Vaux AGC, Medlock JM. Current status of invasive mosquito surveillance in the UK. Parasites Vectors. 2015;8:351.

17. Collantes F, Delacour S, Delgado JA, Bengoa M, Torrell-Sorio A, Guinea H, et al. Updating the known distribution of Aedes albopictus (Skuse, 1894) in Spain 2015. Acta Trop. 2016;164:64-8.

18. Lucientes-Curdi J, Molina-Moreno R, Amela-Heras C, Simón-Soria F, Santos-Sanz S, Sánchez-Gómez A, et al. Dispersion of Aedes albopictus in the Spanish Mediterranean área. Eur J Public Health. 2014;4:637-40.

19. Tappe D, Rissland J, Gabriel M, Emmerich P, Gunther S, Held G, et al. First case of laboratory-confirmed Zika virus infection imported into Europe, November 2013. Eurosurveillance. 2014;19:20685.

20. Alarcón-Elbal PM, Delacour S, Pinar R, Ruiz-Arrondo I, Munoz A, Bengoa $\mathrm{M}$, et al. Establecimiento y mantenimiento de una colonia autóctona española de Aedes (Stegomyia) albopictus Skuse, 1894, (Diptera, Culicidae) en laboratorio. Rev Ibero-Latinoam Parasitol. 2010:69:140-8.

21. Hernández-Triana LM, Fernández de Marco M, Mansfield KL, Thorne L, Lumley S, Marston DA, et al. Assessment of vector competence of UK mosquitoes for Usutu virus of African origin. Parasites Vectors. 2018:11:381.

22. Puggioli A, Carrieri M, Dindo ML, Medici A, Less RS, Gilles JR, Bellini R. Development of Aedes albopictus (Diptera: Culicidae) larvae under different laboratory conditions. J Med Entomol. 2017;54:142-9.

23. Di Luca M, Severini F, Toma L, Boccolini D, Romi R, Remoli ME, et al. Experimental studies of susceptibility of Italian Aedes albopictus to Zika virus. Eurosurveillance. 2016;21:30223.

24. Guzzetta G, Poletti P, Montarsi F, Baldacchino F, Capelli G, Rizzoli A, Rosà R, Merler S. Assessing the potential risk of Zika virus epidemics in temperate areas with established Aedes albopictus populations. Eurosurveillance. 2016;21:30199.

25. Kauffman EB, Kramer LD. Zika virus mosquito vectors: competence, biology, and vector control. J Infect Dis. 2017;216(Suppl. 10):S976-90. 
26. Epelboin Y, Talaga S, Epelboin L, Dusfour I. Zika virus: an updated review of competent or naturally infected mosquitoes. PLoS Negl Trop Dis. 2017;11:e0005933.

27. Heitmann A, Jansen S, Lühken R, Leggewie M, Badusche M, Pluskota B, et al. Experimental transmission of Zika virus by mosquitoes from central Europe. Eurosurveillance. 2017;22:30437.

28. Wong P-SJ, Li MI, Chong C-S, Ng L-C, Tan C-H. Aedes (Stegomyia) albopictus (Skuse): a potential vector of Zika virus in Singapore. PLoS Negl Trop Dis. 2013;7:e2348.

29. Ciota AT, Bialosuknia SM, Zink SD, Brecher M, Ehrbar DJ, Morrissette MN, Kramer LD. Effects of Zika virus strain and Aedes mosquito species on vector competence. Emerg Infect Dis. 2017;23:1110-7.
30. Gutiérrez-López R, Bialosukina SM, Ciota AT, Montalvo T, de la Puente JM, Gangoso L, et al. Vector competence of Aedes caspius and Ae. albopictus mosquitoes for Zika virus, Spain. Emerg Infect Dis. 2019;25:346-8.

31. Jansen S, Heitmann A, Lühken R, Jöst H, Helms M, Vapalahti O, et al. Experimental transmission of Zika virus by Aedes japonicus japonicus from southwestern Germany. Emerg Microb Infect. 2018;7:92.

32. González MA, Pavan MG, Fernandes RS, Núria Busquets N, David MR, et al. Limited risk of Zika virus transmission by five Aedes albopictus populations from Spain. Parasites Vectors. 2019:12:150.

33. Tesla B, Demakovsky LR, Mordecai EA, Ryan SJ, Bonds MH, Ngonghala CN, et al. Temperature drives Zika virus transmission: evidence from empirical and mathematical models. Proc R Soc B Biol Sci. 2018;285:1-9.
Ready to submit your research? Choose BMC and benefit from:

- fast, convenient online submission

- thorough peer review by experienced researchers in your field

- rapid publication on acceptance

- support for research data, including large and complex data types

- gold Open Access which fosters wider collaboration and increased citations

- maximum visibility for your research: over $100 \mathrm{M}$ website views per year

At BMC, research is always in progress.

Learn more biomedcentral.com/submissions 